Article

\title{
Discovery of Novel 1,2,4-Oxadiazole Derivatives as Potent Caspase-3 Activator for Cancer Treatment
}

\author{
Ankur Vaidya \\ Pharmacy College, Uttar Pradesh University of Medical Sciences, Saifai, Etawah 206130, India; \\ ankuruprims@gmail.com
}

check for updates

Citation: Vaidya, A. Discovery of Novel 1,2,4-Oxadiazole Derivatives as Potent Caspase-3 Activator for Cancer Treatment. Chemistry 2021, 3, 373-381. https://doi.org/10.3390/ chemistry3010027

Received: 15 December 2020

Accepted: 1 March 2021

Published: 8 March 2021

Publisher's Note: MDPI stays neutral with regard to jurisdictional claims in published maps and institutional affiliations.

Copyright: (c) 2021 by the author Licensee MDPI, Basel, Switzerland. This article is an open access article distributed under the terms and conditions of the Creative Commons Attribution (CC BY) license (https:// creativecommons.org/licenses/by/ $4.0 /)$.

\begin{abstract}
In the present study, a quantitative structure-activity relationship (QSAR) and docking studies were accomplished on a series of 1,2,4-oxadiazoles. The results of QSARs are reliable and have high predictive ability for both the internal $\left(\mathrm{q}^{2}=0.610\right)$ and external (pred_ $\left.\mathrm{r}^{2}=0.553\right)$ datasets with least standard error (SE; i.e., 0.130) and four principal components, which signifies the reliability of the generated model. Molecular docking was also reported by the GOLD docking program, which showed that the hydrogen bonding may be responsible for the activity, and may be further increased upon adding high electronegative substitutions.
\end{abstract}

Keywords: 1,2,4-oxadiazole; apoptosis; caspase; docking; QSAR

\section{Introduction}

Cancer is the second leading cause of mortality globally and becomes the principal cause of mortality in developing countries [1-3]. Recently, several anticancer drugs have become available on the market, acting through different mechanisms; however, the majority of them are associated with serious side effects [4,5]. The lack of targeting ability of these drugs is responsible for their side effects [6]. Large numbers of heterocyclic compounds have been reported for potential anticancer activities [7]. These heterocyclicbased anticancer agents are either under investigation or marketed as potent anticancer agents [8-11]. Oxadiazole is an important five-membered heterocyclic compound, having one oxygen atom and two nitrogen atoms. Recently, several 1,2,4-oxadiazole derivatives have been shown to possess anticancer activity [12,13].

Nowadays, researchers are focusing on various groups of molecules that are involved in the apoptosis inducing cytotoxicity. Caspases, a group of cysteine proteases, are the executioners of apoptosis. These caspases cleave their substrates after aspartic acid residues. Initiator caspases (caspase 2/8/9/10) and effector caspases (caspase 3/6/7) are the two classes of caspase. Recently, the activation of caspase- 3 mediated apoptosis becomes an interesting therapeutic strategy for cancer therapy. Zhang et al. reported a series of 3Aryl-5-aryl-1,2,4-oxadiazoles as a novel apoptosis inducer through caspase-3 activation. The compounds' activities have been reported against breast and colorectal cancer cell lines [14].

The quantitative structure-activity relationship (QSARs) is an attempt to correlate the structural features of the compounds quantitatively with their biological activities. Researchers reported thousands of QSAR studies in the search for novel anticancer agents [15-19].

In the search for new anticancer agents, our research group previously reported QSAR studies of 1,2,4-oxadiazole derivatives describing the key structure features responsible for anticancer activities [20-22]. In the continuation of our previous work, herein we report the two-dimensional QSAR (2D-QSAR) and molecular docking studies' outcomes.

The 2D-QSAR studies were done using Step Wise k Nearest Neighbor Molecular Field Analysis [(SW) kNN MFA] using V-Life Molecular Design Software Version 3.0 (V-Life Molecular Design). The docking studies were also performed using GOLD software. 


\section{Material and Methods}

\subsection{Dataset}

A dataset of twenty eight 3-aryl-5-aryl-1,2,4-oxadiazoles derivatives has been taken for present QSAR study (Table 1). Compounds have high structural diversity with ample range of biological activity [14,23].

Table 1. 1,2,4-Oxadiazole analogues and their experimental caspase-3 activator activity.

\begin{tabular}{|c|c|c|c|c|}
\hline S. No. & Compound & $\mathrm{Ar}_{1}$ & $\mathrm{Ar}_{2}$ & $\begin{array}{c}\text { Experimental Activity } \\
p \mathrm{EC}_{50}(\mathrm{nM}) \text { (DLD1) }\end{array}$ \\
\hline 1 & 1d & & & 3.357 \\
\hline 2 & $4 a$ & & & 3.102 \\
\hline 3 & $4 b$ & & & 3.119 \\
\hline 4 & $4 c$ & & & 3.367 \\
\hline 5 & $4 d$ & & & 2.839 \\
\hline 6 & $4 e$ & & & 2.848 \\
\hline 7 & $4 g$ & & & 3.553 \\
\hline 8 & $4 h$ & & & 3.432 \\
\hline 9 & $4 \mathrm{i}$ & & & 3.252 \\
\hline
\end{tabular}


Table 1. Cont.

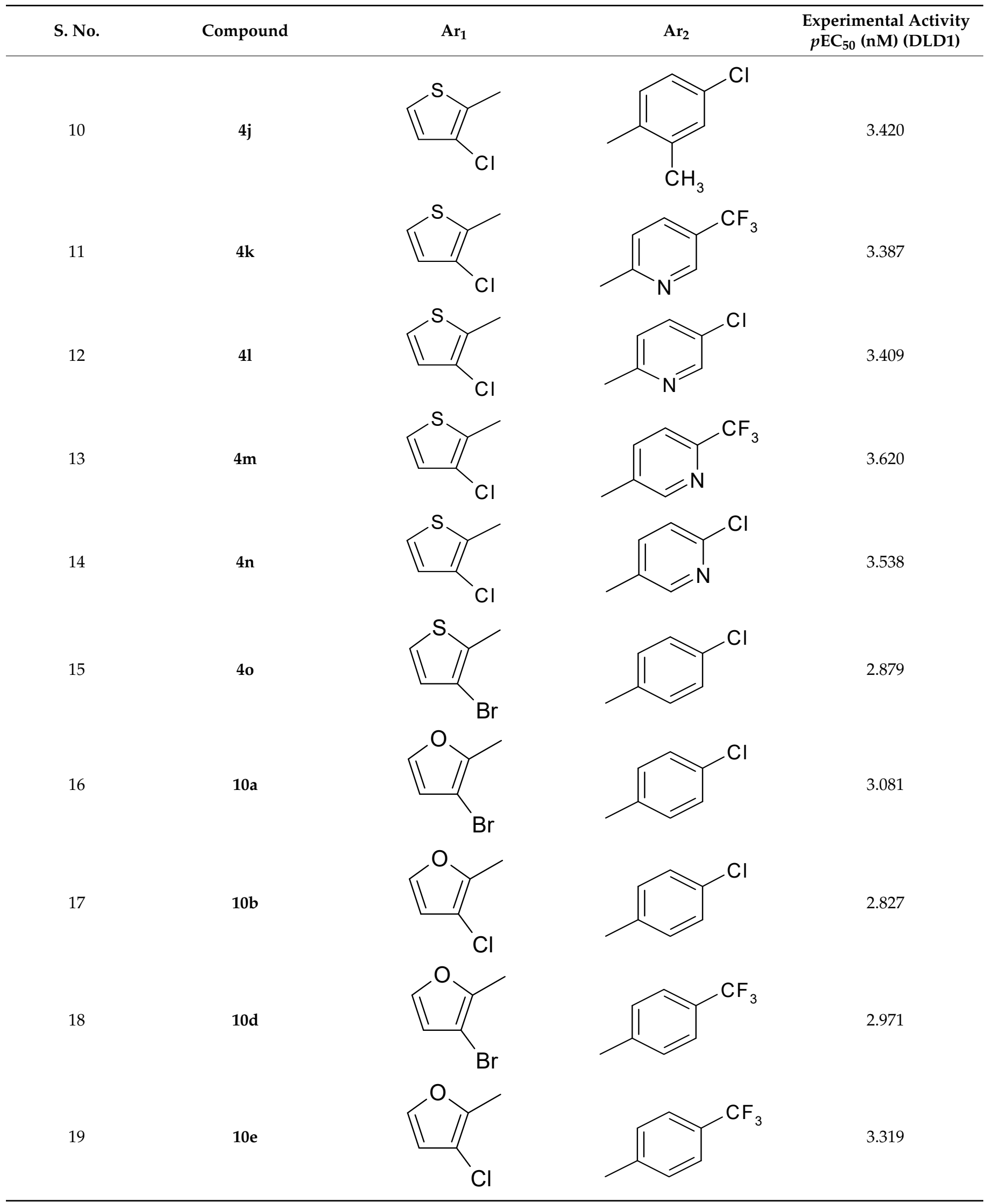


Table 1. Cont.

\begin{tabular}{|c|c|c|c|c|}
\hline S. No. & Compound & $\mathrm{Ar}_{1}$ & $\mathrm{Ar}_{2}$ & $\begin{array}{l}\text { Experimental Activity } \\
p \mathrm{EC}_{50} \text { (nM) (DLD1) }\end{array}$ \\
\hline 20 & $10 \mathrm{f}$ & & & 3.076 \\
\hline 21 & $10 \mathrm{~g}$ & & & 3.155 \\
\hline 22 & $10 \mathrm{~h}$ & & & 3.237 \\
\hline 23 & 11a & & & 3.229 \\
\hline 24 & $11 \mathrm{~b}$ & & & 3.236 \\
\hline 25 & 11c & & & 2.959 \\
\hline 26 & $11 \mathrm{~d}$ & & & 2.959 \\
\hline 27 & 11e & & & 3.149 \\
\hline 28 & $11 \mathrm{f}$ & & & 2.921 \\
\hline
\end{tabular}




\section{2. $2 D Q S A R$}

2D QSAR studies were performed via Step Wise k Nearest Neighbor Molecular Field Analysis [(SW) kNN MFA] method using V-Life Molecular Design Software Version 3.0 (V-Life Molecular Design) [24-26].

The 2D QSAR studies were performed by dividing compounds in the training and test dataset which resulted several QSAR equations. Unicolumn statistics was done to divide training and test data compounds. Twenty-two compounds were positioned in the training set and 6 compounds $(\mathbf{4 b}, 4 \mathrm{~d}, 4 \mathbf{e}, \mathbf{1 0 a}, \mathbf{1 0 d}$ and $11 \mathrm{~h})$ in the test set.

\subsection{Molecular Docking Analysis}

Molecular docking was employed to locate the appropriate binding orientations and conformations of these 1,2,4-oxadiazoles interacting with caspase-3 using the docking program GOLD version 3.2. Ten docked conformers were produced for each 1,2,4-oxadiazole derivative. The conformation with the lowest docking energy in the most populated cluster is selected as the possible "active" conformation against the 1RE1 active site. In the present study, 28 compounds were successfully docked into the 1RE1 site.

The X-ray crystal structure (pdb: 1RE1) of caspase-3 was obtained from the Protein Data Bank. Initially, for protein preparation, water molecules were removed, hydrogen atoms added and AMBER7FF99 charges to the protein were applied. The ligands were docked inside a cubic GRID box (within $5 \mathrm{~A}^{\circ}$ surrounding to the cocrystallized ligand) centered at the midpoint between the Cys205 and Gly238. Ten docking runs were performed for each compound in the dataset. In most cases the chosen pose was the top ranked solution.

\section{Results and Discussion}

\subsection{D QSAR Results}

The results of the unicolumn statistics are summarized in Table 2, which showed that the test is interpolative i.e., both test and training dataset contain compounds of high structure diversity with variation in biological activity. The test and the training set contained a diverse set of compounds with low, moderate and high biological activity.

Table 2. Unicolumn statistical data of training and test set in 2D quantitative structure-activity relationship (QSAR) models.

\begin{tabular}{ccccc}
\hline & Average & Maxima & Minima & Std. Deviation \\
\hline Training set & 3.174 & 3.620 & 2.827 & 0.228 \\
\hline Test set & 3.234 & 3.553 & 2.848 & 0.264 \\
\hline
\end{tabular}

Finally, the following model was selected.

$$
p \mathrm{EC}_{50}=0.243 * \mathrm{IP}-0.139 * \mathrm{BC}+0.155 * \mathrm{DM}+0.008 * \mathrm{PSA}+0.0005
$$

The obtained model showed a high correlation coefficient $(\mathrm{r}=0.862)$ between descriptors including ionization potential (IP), bromine count (BC), dipole moment (DM), polar surface area (PSA) and anticancer activities. The squared correlation coefficient $\left(\mathrm{r}^{2}\right)$ of 0.743 , explains $74.29 \%$ of the variance in biological activity. The obtained model is statistical significant with $F$ values $F(4,21)=11.561$. The obtained model showed both good internal and external predictive ability with cross-validated squared correlation coefficient for internal dataset $\left(\mathrm{q}^{2}\right)$ value 0.610 and for external dataset $\left(\right.$ pred_r $\left.^{2}\right)$ value 0.553 with a standard error (SE) of 0.130 (Table 3).

Table 3. Parameters value for the best 2D QSAR model generated.

\begin{tabular}{cccccccc}
\hline Model & $\mathbf{r}$ & $\mathbf{r}^{2}$ & $\mathbf{q}^{2}$ & SE $\left(\mathbf{r}^{2} \mathbf{s e}\right)$ & Pred_r $\mathbf{r}^{2}$ & F-Value & Descriptors \\
\hline 1 & 0.862 & 0.743 & 0.610 & 0.130 & 0.553 & 11.561 & IP, BC, DM, PSA \\
\hline
\end{tabular}


In the model, the contribution of the descriptors is presented in the contribution chart (Figure 1), signifying the positive contribution of the ionization potential (IP), dipole moment (DM) and polar surface area (PSA) towards the biological activity. The addition of substitution that increases the polarity of the compounds results in increased anticancer activity. The negative contribution of the bromine count signifies the lower number of bromine encouraging biological activities.

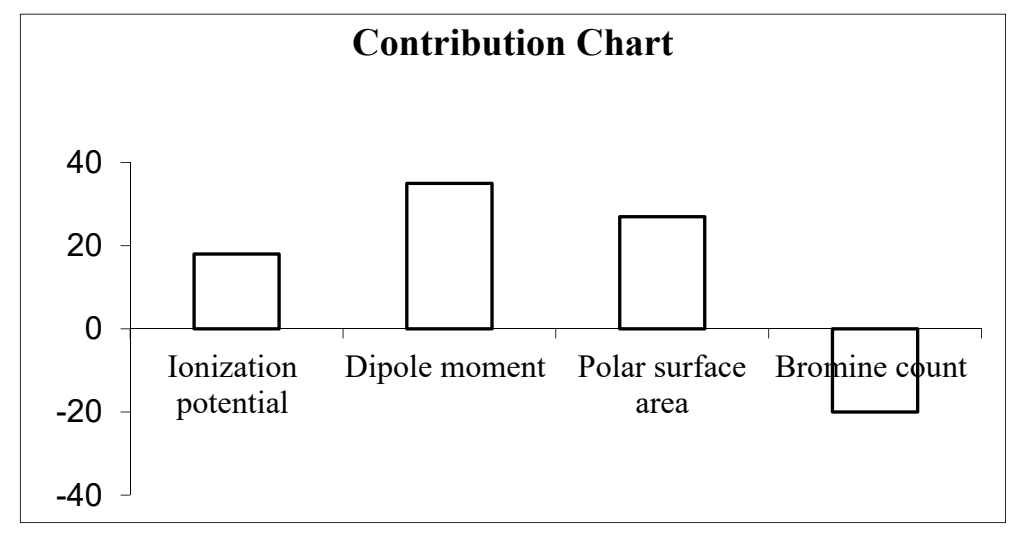

Figure 1. Contribution chart of descriptors in 2D QSAR model.

The correlation between the experimental and predicted activity of the compounds is shown in Table 4 and represented in Figure 2.

Table 4. Experimental, predicted and residual activities of the compounds obtained in 2D QSAR and GOLD score.

\begin{tabular}{|c|c|c|c|c|}
\hline \multirow[b]{2}{*}{ Comp. No. } & \multirow[b]{2}{*}{$\begin{array}{l}\text { Experimental } \\
p \mathrm{EC}_{50}\end{array}$} & \multicolumn{2}{|c|}{ 2D QSAR } & \multirow{2}{*}{$\begin{array}{c}\text { Docking } \\
\text { GOLD Docking }\end{array}$} \\
\hline & & $\begin{array}{c}{[(\mathrm{SW}) \mathrm{kNN} \text { MFA] Predicted }} \\
p \mathrm{EC}_{50}\end{array}$ & $\begin{array}{l}\text { [(SW) kNN MFA] } \\
\text { Residual }\end{array}$ & \\
\hline 1d & 3.357 & 3.291 & 0.065 & 50.771 \\
\hline $4 a$ & 3.102 & 3.155 & -0.052 & 48.324 \\
\hline $4 b$ & 3.119 & 3.106 & 0.013 & 47.105 \\
\hline $4 c$ & 3.367 & 3.300 & 0.067 & 51.672 \\
\hline $4 d$ & 2.839 & 2.912 & -0.074 & 52.859 \\
\hline $4 e$ & 2.848 & 3.102 & -0.255 & 50.846 \\
\hline $4 g$ & 3.553 & 3.269 & 0.284 & 50.357 \\
\hline $4 \mathrm{~h}$ & 3.432 & 3.306 & 0.126 & 50.212 \\
\hline $4 i$ & 3.252 & 3.382 & -0.130 & 50.304 \\
\hline $4 j$ & 3.420 & 3.106 & 0.315 & 56.319 \\
\hline $4 \mathrm{k}$ & 3.387 & 3.415 & -0.028 & 50.294 \\
\hline 41 & 3.409 & 3.361 & 0.048 & 51.432 \\
\hline $4 m$ & 3.620 & 3.620 & -0.0002 & 49.303 \\
\hline $4 n$ & 3.538 & 3.532 & 0.005 & 50.930 \\
\hline 40 & 2.879 & 3.025 & -0.146 & 50.968 \\
\hline $10 a$ & 3.081 & 2.899 & 0.182 & 49.383 \\
\hline $10 \mathrm{~b}$ & 2.827 & 3.045 & -0.218 & 49.680 \\
\hline $10 d$ & 2.971 & 3.128 & -0.157 & 50.205 \\
\hline $10 \mathrm{e}$ & 3.319 & 3.233 & 0.086 & 51.265 \\
\hline $10 \mathrm{f}$ & 3.076 & 3.162 & -0.086 & 49.302 \\
\hline $10 \mathrm{~g}$ & 3.155 & 3.253 & -0.098 & 49.203 \\
\hline $10 \mathrm{~h}$ & 3.237 & 3.295 & -0.058 & 49.839 \\
\hline $11 a$ & 3.229 & 3.102 & 0.127 & 50.212 \\
\hline $11 b$ & 3.236 & 3.234 & 0.003 & 49.423 \\
\hline $11 c$ & 2.959 & 3.007 & -0.049 & 45.962 \\
\hline $11 d$ & 2.959 & 3.007 & -0.049 & 47.860 \\
\hline $11 \mathrm{e}$ & 3.149 & 2.927 & 0.222 & 49.377 \\
\hline $11 \mathrm{f}$ & 2.921 & 2.879 & 0.042 & 50.891 \\
\hline
\end{tabular}




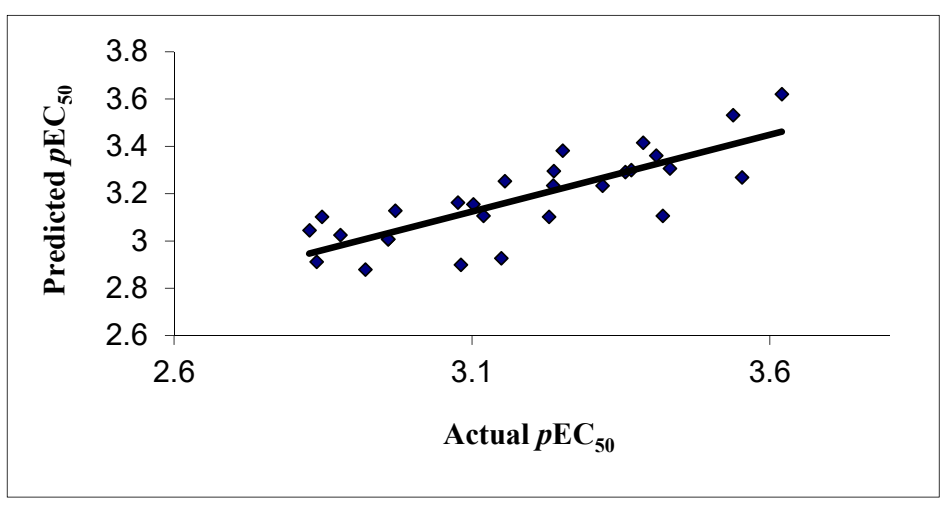

Figure 2. Correlation of experimental and predicted activity in 2D QSAR model.

\subsection{GOLD Docking Studies}

All 28, 1,2,4-oxadiazoles derivatives were docked into the binding site of caspase-3 and the energy scores of the activators are also shown in Table 4. A precise correlation was observed in between docking scores and $p \mathrm{IC}_{50}$ values.

A complete overview of GOLD docking is presented in Figures 3 and 4.

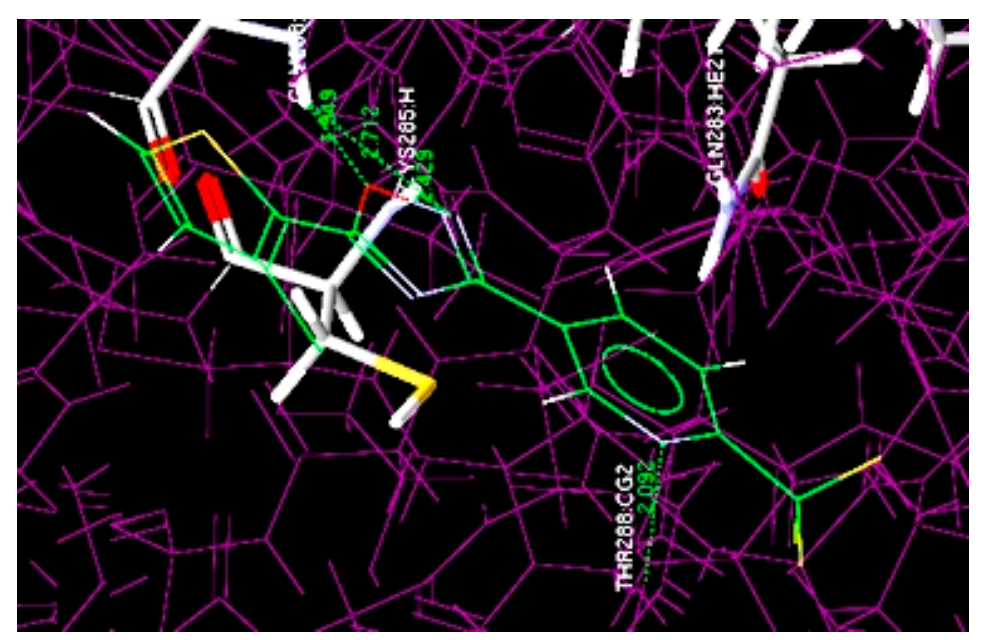

Figure 3. Overlay of docked highest potent oxadiazole compound (4m) at the active site of 1RE1.

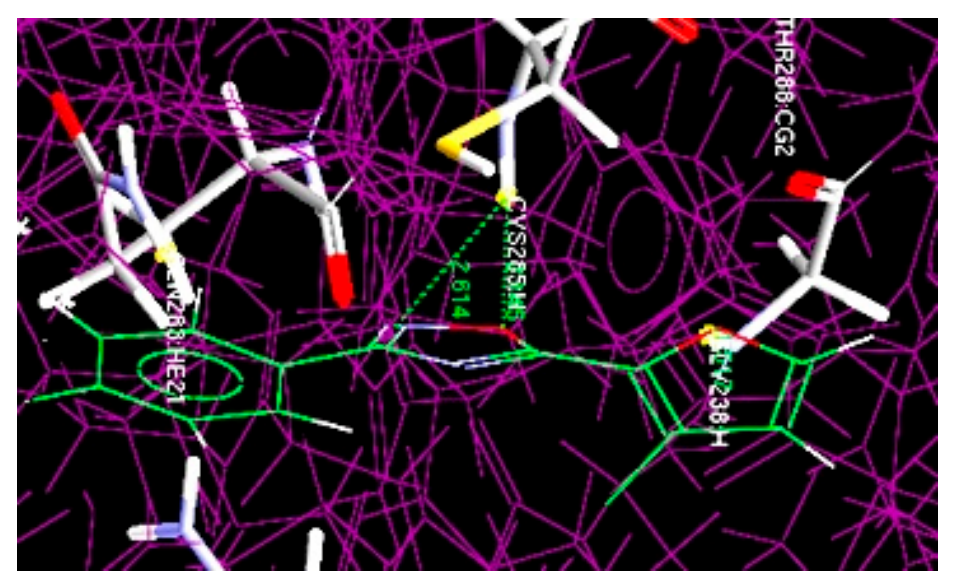

Figure 4. Overlay of docked least potent oxadiazole compound (10b) at the active site of 1RE1.

The docking results revealed that most active compound $4 \mathrm{~m}$ is properly located at the binding site of the Cys205 and Gly238 amino acid residues and numerous interactions occur between it and the binding region of the enzyme. The four key hydrogen bond interactions 
occur: (1) between the $\mathrm{NH}$ of Gly238 and the $\mathrm{O}$ of the oxadiazole ring; (2) between the $\mathrm{NH}$ of Gly238 and the $\mathrm{N}$ of the oxadiazole ring; (3) between the $\mathrm{NH}$ of Cys285 and the $\mathrm{N}$ of the oxadiazole ring; (4) between the $\mathrm{NH}$ of THR288 and the $\mathrm{N}$ of the pyridine ring residue (Figure 3). The hydrogen bonding distances observed were $1.549 \AA$ (O $\cdots \mathrm{H}-\mathrm{NH}-\mathrm{Gly} 238)$,

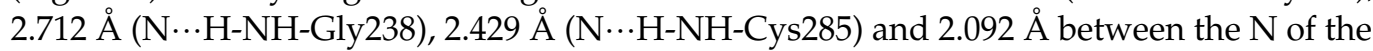
pyridine ring and $\mathrm{NH}$ of THR288 ( $\mathrm{N} \cdot \cdots \mathrm{H}-\mathrm{NH}-\mathrm{THR} 288)$.

Akin to compound $4 \mathrm{~m}$, compound $10 \mathrm{~b}$ was also docked at the same binding pockets having Cys205 and Gly238 amino acid residues (Figure 4). The result showed the formation of two hydrogen bonds: (1) between the $\mathrm{NH}$ of Cys205 and the $\mathrm{O}$ of the oxadiazole ring (O...H-NH-Cys205), having $2.145 \AA$ bond distance; (2) between the NH of Cys205 and the $\mathrm{N}$ of the oxadiazole ring (N...H-NH-Cys205) with $2.614 \AA$ bond length.

The docking results revealed that the hydrogen bonding may be responsible for biological activity, which may be further increase upon adding more electronegative substitutions. The correlation between the dock score and the experimental activity is shown graphically in Figure 5, which shows a linear correlation between the dock score and biological activity.

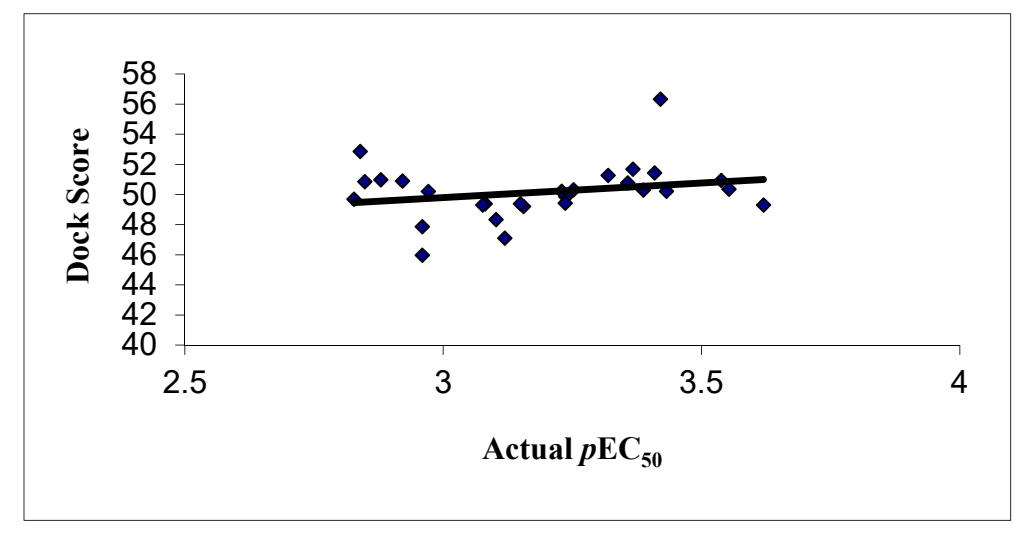

Figure 5. Correlation between the experimental activities and dock score in GOLD docking.

The results of the QSAR analysis clearly show that upon increasing the polarity in terms of theionization potential (IP), dipole moment (DM) and polar surface area (PSA), biological activity will also be enhanced. The docking results also support the QSAR outcomes.

\section{Conclusions}

In conclusion, the current QSAR studies established a reliable QSAR model with high predictive ability with $\mathrm{q}^{2}=0.610, \mathrm{r}^{2}=0.743$ and low standard error $(\mathrm{SE})=0.130$ and four principal components. The predicted value of the external test set (pred_r $\mathrm{r}^{2}$ ) was also high (i.e., 0.553). The developed model was reliable, which indicated the importance of substitution in 1,2,4-oxadiazoles at their respective positions to improve anticancer activity. The positive contribution of ionization potential (IP), dipole moment (DM) and polar surface area (PSA) is conducive for biological activity, and further addition of these substitutions increases anticancer activity, while the negative contribution of the bromine count signifies the lower number of bromine encouraging the biological activities. The docking results explore the binding mode between the ligands and the receptor.

Funding: This research received no external funding.

Data Availability Statement: Data available in article and raw data are available from the corresponding authors upon request.

Acknowledgments: We would like to thank G. Narahari Sastry, former head of the department, Molecular Modeling Group, IICT Hyderabad, India, for providing access to computational resources and for their valuable help during the modeling studies. 
Conflicts of Interest: The authors declare that they have no conflict of interest.

\section{References}

1. Thun, M.J.; Henley, S.J.; Burns, D.; Jemal, A.; Shanks, T.G. Lung cancer death rates in lifelong nonsmokers. J. Natl. Cancer Inst. 2006, 98, 691-699. [CrossRef]

2. Jain, S.; Pathak, K.; Vaidya, A. Molecular therapy using siRNA: Recent trends and advances of multi target inhibition of cancer growth. Int. J. Biol. Macromol. 2018, 116, 880-892. [CrossRef] [PubMed]

3. Vaidya, A.; Jain, S.; Sahu, S.; Jain, P.K.; Pathak, K.; Pathak, D.; Kumar, R.; Jain, S.K. Anticancer agents based on vulnerable components in a signalling pathway. Mini Rev. Med. Chem. 2020, 20, 886-907. [CrossRef] [PubMed]

4. Ayati, A.; Emami, S.; Asadipour, A.; Shafiee, A.; Foroumadi, A. Recent applications of 1,3-thiazole core structure in the identification of new lead compounds and drug discovery. Eur. J. Med. Chem. 2015, 97, 699-718. [CrossRef]

5. Vaidya, A.; Jain, S.; Jain, A.K.; Agrawal, A.; Kashaw, S.K.; Jain, S.K.; Agrawal, R.K. Metabotropic Glutamate Receptors: A Review on Prospectives and Therapeutic Aspects. Mini Rev. Med. Chem. 2013, 12, 1967-1981. [CrossRef]

6. Jain, S.; Vaidya, A.; Jain, A.K.; Agrawal, R.K.; Kashaw, S.K. Computational analysis of benzyl vinylogous derivatives as potent PDE3B inhibitors. Arab. J. Chem. 2017, 10, S109-S113. [CrossRef]

7. Jain, A.K.; Vaidya, A.; Ravichandran, V.; Kashaw, S.K. Recent Developments and Biological Activities of Thiazolidinone Derivatives: A Review. Bioorg. Med. Chem. 2012, 20, 3378-3395. [CrossRef]

8. Jain, A.K.; Sharma, S.; Vaidya, A.; Ravichandran, V.; Agrawal, R.K. 1,3,4-Thiadiazole and Its Derivatives: A Review on Recent Progress in Biological Activities. Chem. Biol. Drug. Des. 2013, 81, 557-576. [CrossRef] [PubMed]

9. Jain, S.; Pattnaik, S.; Pathak, K.; Kumar, S.; Pathak, D.; Jain, S.K.; Vaidya, A. Anticancer Potential of Thiazole Derivatives: A Retrospective Review. Mini Rev. Med. Chem. 2017, 18, 640-655. [CrossRef]

10. Vaidya, A.; Jain, S.; Jain, A.K.; Prashanthakumar, B.R.; Kashaw, S.K.; Agrawal, R.K. Computational Analysis of Quinoline Derivatives as Potent Topoisomerase-II Inhibitors. Med. Chem. Res. 2015, 24, 383-393. [CrossRef]

11. Jain, S.; Chandra, V.; Pankaj Kumar, J.; Pathak, K.; Pathak, D.; Vaidya, A. Comprehensive review on current developments of quinoline-based anticancer agents. Arab. J. Chem. 2019, 12, 4920-4946. [CrossRef]

12. Anjos, J.V.; Ricardo, A.W.; Filho, N.; Nascimento, S.C.; Srivastava, R.M.; Melo, S.; Sinou, D.J. Synthesis and cytotoxic profile of glycosyl-triazole linked to 1,2,4-oxadiazole moiety at C-5 through a straight-chain carbon and oxygen atoms. Eur. J. Med. Chem. 2009, 44, 3571-3576. [CrossRef]

13. Vaidya, A.; Jain, S.; Jain, P.; Jain, P.; Tiwari, N.; Jain, R.; Jain, R.; Jain, A.K.; Agrawal, R.K. Synthesis and Biological Activities of Oxadiazole Derivatives: A Review. Mini Rev. Med. Chem. 2016, 16, 825-845. [CrossRef]

14. Zhang, H.Z.; Kaisbhatla, S.; Kuemmerle, J.; Kemnitzer, W.; Mason, K.O.; Qui, L.; Grundy, C.C.; Tseng, B.; Drew, J.; Cai, S.X. Discovery and Structure-Activity Relationship of 3-Aryl-5-aryl-1,2,4-oxadiazoles as a New Series of Apoptosis Inducers and Potential Anticancer Agents. J. Med. Chem. 2005, 48, 5215-5223. [CrossRef]

15. Bhatiya, R.; Vaidya, A.; Kashaw, S.K.; Jain, A.K.; Agrawal, R.K. QSAR analysis of furanone derivatives as potential COX-2 inhibitors: kNN MFA approach. J. Saudi Chem. Soc. 2014, 18, 977-984. [CrossRef]

16. Vaidya, A.; Jain, S.; Jain, S.; Jain, A.K.; Agrawal, R.K. Quantitative Structure-Activity Relationships: A Novel Approach of Drug Design and Discovery. J. Pharm. Sci. Pharmacol. 2014, 1, 219-232. [CrossRef]

17. Agrawal, R.K.; Jain, A.K.; Veerasamy, R.; Vaidya, A.; Kashaw, S.; Mourya, V.K.; Agrawal, R.K. QSAR analysis of B-ring-modified diaryl ether derivatives as a InhA inhibitors. Med. Chem. Res. 2012, 21, 145-151.

18. Vaidya, A.; Jain, A.K.; Kumar, P.; Kashaw, S.K.; Agrawal, R.K. Predicting anti-cancer activity of quinoline derivatives: CoMFA and CoMSIA approach. J. Enzyme Inhib. Med. Chem. 2011, 26, 854-861. [CrossRef] [PubMed]

19. Jain, A.K.; Veerasamy, R.; Vaidya, A.; Mourya, V.; Agrawal, R.K. QSAR analysis of some novel sulfonamides incorporating 1,3,5-triazine derivatives as carbonic anhydrase inhibitors. Med. Chem. Res. 2010, 19, 1191-1202. [CrossRef]

20. Vaidya, A.; Jain, A.K.; Kumar, B.R.P.; Sastry, G.N.; Kashaw, S.K.; Agrawal, R.K. CoMFA, CoMSIA, kNN MFA and Docking studies of 1.;2.;4-Oxadiazole derivatives as potent Caspase-3 activators. Arab. J. Chem. 2017, 10, S3936-S3946. [CrossRef]

21. Vaidya, A.; Jain, S.; Kumar, B.R.P.; Singh, S.K.; Kashaw, S.K.; Agrawal, R.K. Synthesis of 1,2,4-oxadiazole derivatives: Anticancer and 3D QSAR studies. Mon. Chem. 2020, 151, 385-395. [CrossRef]

22. Vaidya, A.; Pathak, D.; Shah, K. 1,3,4-oxadiazole and its Derivatives: A Review on Recent Progress in Anticancer Activities. Chem. Biol. Drug Des. 2020, 97, 572-591. [CrossRef] [PubMed]

23. Kemnitzer, W.; Kuemmerle, J.; Zhang, H.Z.; Kaisbhatla, S.; Tseng, B.; Drew, J.; Cai, S.X. Discovery of 3-aryl-5-aryl-1,2,4-oxadiazoles as a new series of apoptosis inducers. 2. Identification of more aqueous soluble analogs as potential anticancer agents. Bioorg. Med. Chem. Lett. 2009, 19, 4410-4415. [PubMed]

24. Roy, K.; Das, R.N. A review on principles, theory and practices of 2D-QSAR. Curr. Drug. Metab. 2014, 15, 346-379. [CrossRef] [PubMed]

25. Adhikari, C.; Mishra, B.K. Quantitative Structure-Activity Relationships of Aquatic Narcosis: A Review. Curr. Comput. Aided Drug Des. 2018, 14, 7-28. [CrossRef] [PubMed]

26. Lewis, R.A.; Wood, D. Modern 2D QSAR for drug discovery. Wiley Interdiscip. Rev. Comput. Mol. Sci. 2014, 4, 505-522. [CrossRef] 